\title{
Effect of the Dispersibility of Nano-CuO Catalyst on Heat Releasing of AP/HTPB Propellant
}

\author{
Yi Yang, Xinjie Yu, Jun Wang, and Yaxue Wang \\ School of Chemical Engineering, Nanjing University of Science and Technology, Nanjing 210094, China \\ Correspondence should be addressed to Yi Yang, yyi301@163.com
}

Received 30 May 2010; Accepted 1 August 2010

Academic Editor: Quanqin Dai

Copyright () 2011 Yi Yang et al. This is an open access article distributed under the Creative Commons Attribution License, which permits unrestricted use, distribution, and reproduction in any medium, provided the original work is properly cited.

Kneading time is adjusted to change the dispersibility of nano-CuO in AP/HTPB (Ammonia Perchlorate/Hydroxyl-Terminated Polybutadiene) composite propellants. Nano-CuO/AP is prepared to serve as the other dispersing method of nano-CuO, named predispersing procedure. Several kinds of heat releasing, thermal decomposition by DSC, combustion heat in oxygen environment, and explosion heat in nitrogen environment, are characterized to learn the effect of dispersibility of nano-CuO catalyst on heat releasing of propellants. With pre-dispersing procedures, thermal decomposition temperature of nano-CuO/AP and its propellant are about $25^{\circ} \mathrm{C}$ and $8.6^{\circ} \mathrm{C}$ lower than that of AP simple mixed with nano- $\mathrm{CuO}$ and its propellant, respectively. Comparing propellant with simple mixed nano-CuO kneading 3 hours, combustion heat and explosion heat of propellant with nano$\mathrm{CuO} / \mathrm{AP}$ increase about $1.4 \%$ and $1.7 \%$, respectively. However, because of the breaking of nano-CuO/AP structure during kneading procedure, combustion heat and explosion heat of all the samples are decreased with the increase of kneading time after 3 hours.

\section{Introduction}

In recent years, there has been an explosion of interest in the synthesis, structure, properties, and applications of nanomaterials, mainly because of the fact that materials confined in one or more dimension can exhibit interesting properties, such as catalysis. Copper oxide $(\mathrm{CuO})$ has been reported as a thermal decomposition catalyst of AP (Ammonia Perchlorate, $\mathrm{NH}_{4} \mathrm{ClO}_{4}$ ) [1]. It naturally becomes a traditional combustion catalyst of AP/HTPB (HydroxylTerminated Polybutadiene) composite propellants. As a result of the development of nanotechnology, researches on nanocatalysts, including nanometer $\mathrm{CuO}$, are surged up. However, most researches tend to focus on the catalysis of the diameter or variety of nanomaterials $[2,3]$. Although some of them emphasized the dispersibility improvement technologies of nanomaterials, little attention has been paid to the relationship between dispersibility and catalysis of nanomaterials.

Heat releasing or energy releasing is one of the most important properties of thermal decomposition and combustion of propellants. Catalysts always play a key role in heat releasing procedure of propellant. As one of the most important factors of nanomaterials, dispersibility plays a key role in the effect of catalysis of nanomaterials. Because of little diameter and proportion, nanocatalyst becomes the most difficult dispersing composition of many combustion systems. However, the excellent catalysis of nanocatalyst still attracts many researchers to study [4-6]. As nanocatalysts likely perform much higher catalysis efficiency than microcatalysts, the dispersibility of nanocatalysts is much important than that of microcatalysts. On the other hand, the dispersibility of nanocatalysts also affected its catalysis crucially [7-9]. Therefore, the dispersibility of nanocatalyst is very important to the heat releasing of propellants.

In this paper, kneading time has been ranged from 1 hour to 5 hours to improve the dispersibility of nano$\mathrm{CuO}$ combustion catalyst in composite propellant. Predispersing procedure has been applied to the propellant by adding nano-CuO/AP composite particles instead of simple mixture of nano- $\mathrm{CuO}$ and $\mathrm{AP}$. Several kinds of heat releasing, thermal decomposition by DSC, combustion heat in oxygen environment, and explosion heat in nitrogen environment, have been tested to check the relationship of heat releasing with the dispersibility of nano- $\mathrm{CuO}$ catalyst in AP/HTPB composite propellants. 
TABLE 1: Thermal decomposition temperature of $\mathrm{HTPB}$ propellant with nano-CuO particles.

\begin{tabular}{|c|c|c|c|c|c|c|}
\hline Kneading Time (h) & Area $1\left({ }^{\circ} \mathrm{C}\right)$ & Area $2\left({ }^{\circ} \mathrm{C}\right)$ & Area $3\left({ }^{\circ} \mathrm{C}\right)$ & Mean Value $\left({ }^{\circ} \mathrm{C}\right)$ & STD $\left({ }^{\circ} \mathrm{C}\right)$ & RSD (\%) \\
\hline $1 \mathrm{~h}$ & 321.51 & 337.98 & 310.07 & 323.19 & 14.03 & 4.34 \\
\hline $2 \mathrm{~h}$ & 319.59 & 328.42 & 310.93 & 319.65 & 8.75 & 2.74 \\
\hline $3 \mathrm{~h}$ & 308.55 & 316.17 & 303.64 & 309.45 & 6.31 & 2.04 \\
\hline $4 \mathrm{~h}$ & 302.33 & 300.47 & 308.18 & 303.66 & 4.02 & 1.32 \\
\hline $5 \mathrm{~h}$ & 298.07 & 293.87 & 300.96 & 297.63 & 3.57 & 1.20 \\
\hline
\end{tabular}

\section{Experimental Procedures}

Nanometer copper oxide $(\mathrm{CuO}), 40 \mathrm{~nm}$ in average diameter, was used as the combustion catalyst in AP/HTPB composite solid propellant. Kneading machine was used to disperse nanocatalyst as well as other compositions of AP/HTPB propellant. Kneading time ranged from 1 to 5 hours to change the dispersibility of nano-CuO catalyst in the propellant.

QM-ISP2-CL model planetary ball mill was used to prepare the nano- $\mathrm{CuO} / \mathrm{AP}$ composite particles. The predispersing method was applied to improve the dispersibility of nano- $\mathrm{CuO}$ before adding it into the propellant. First, nano- $\mathrm{CuO}$ was dispersed in ethanol by ultrasonic. Then AP was mixed with the nano- $\mathrm{CuO}$ with the weight ratio of $4: 1$. The mixture was milled in the planetary ball mill for 30 minutes at $70 \mathrm{rpm}$. Nano-CuO/AP composite particles were obtained by drying and grinding the milled mixture. When the catalyst added in the propellant in the form of nano$\mathrm{CuO} / \mathrm{AP}$ composite, the amount of AP was deducted from the original proportion.

To test thermal decomposition temperature of AP and AP/HTPB propellant, DSC studies were performed with the USA SDTQ-600 differential scanning calorimeter under an atmosphere of $\mathrm{N}_{2}$ (at a rate of $20 \mathrm{~mL} / \mathrm{min}$ ) and at a heating rate of $10 \mathrm{k} / \mathrm{min}$. XRY-1C oxidation bomb calorimeter was applied to test combustion heat (in $3 \mathrm{MPa}_{2}$ environment) and explosion heat (in $3 \mathrm{MPa} \mathrm{N}_{2}$ environment) of AP/HTPB propellant.

\section{Results and Discussions}

3.1. DSC Thermal Decomposition of AP. Ammonia Perchlorate $(\mathrm{AP})$ is one of the main compositions of $\mathrm{AP} / \mathrm{HTPB}$ composite propellant. The content of AP is up to 70 percent in the composite propellant. Most catalysts in the composite propellant act on the composition of AP. Therefore, many researches study the catalysis of nanocatalyst on AP/HTPB propellant by testing the thermal decomposition of AP with nanocatalyst $[10,11]$. Figure 1 shows thermal decomposition curves of AP tested by DSC.

High-decomposition temperatures of AP are decreased $112.83^{\circ} \mathrm{C}$ and $137.62^{\circ} \mathrm{C}$ by adding with simple mixed nano$\mathrm{CuO}$ and nano- $\mathrm{CuO} / \mathrm{AP}$ composite catalysts, respectively. The nanometer catalysts show excellent catalysis on the thermal decomposition of AP. While the thermal decomposition temperature of nano- $\mathrm{CuO} / \mathrm{AP}$ composite is much lower than that of AP simple mixed with nano-CuO. Better catalysis on $\mathrm{AP}$ of nano-CuO can be attributed to better dispersibility of nano- $\mathrm{CuO}$ catalyst. Simple mixing method is difficult to

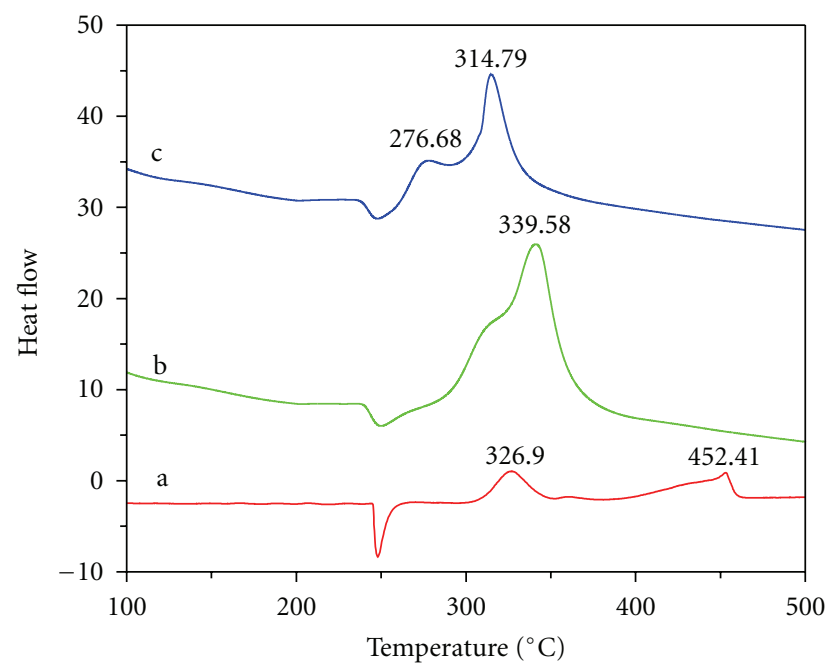

FIGURE 1: DSC thermal decomposition curves of AP. (a) pure AP; (b) nano- $\mathrm{CuO}$ simple mixed with $\mathrm{AP}$; (c) nano-CuO/AP composite.

get enough dispersibility of nanocatalyst in AP, while the dispersibility of nano-CuO can be improved at a perfect level in the form of nano-CuO/AP composite particles.

3.2. DSC Thermal Decomposition of Propellant. Table 1 shows the thermal decomposition temperature data of HTPB propellant with nano-CuO catalyst. The kneading time of each sample ranged from 1 hour to 5 hours. Three representative areas of each sample were chosen to test its decomposition temperature by DSC. Standard deviation (STD) and relative standard deviation (RSD) of the test results of each sample were calculated and listed in Table 1.

Kneading procedures are always employed to improve the composition dispersity of HTPB propellants as well as nano$\mathrm{CuO}$ catalyst. Because of little diameter and proportion, nanocatalyst becomes the most difficult dispersing composition of HTPB propellants. Therefore, the dispersity of nanocatalyst becomes one of the key factors of propellant properties, including its heat releasing amount and procedures. From Table 1, as the kneading time increase, the mean values of decomposition temperature of samples decease smoothly from $323.19^{\circ} \mathrm{C}$ to $297.63^{\circ} \mathrm{C}$. HTPB propellants with higher dispersity of nano-CuO catalyst show lower decomposition temperature. Meanwhile, the RSD values of samples decrease from $4.34 \%$ to $1.20 \%$ with the increase of kneading time. It means that the increasing of nano$\mathrm{CuO}$ dispersibility in HTPB propellant not only decreases the 
TABLE 2: Thermal decomposition temperature of HTPB propellant with nano-CuO/AP composite.

\begin{tabular}{|c|c|c|c|c|c|c|}
\hline Kneading Time (h) & Area $\mathrm{I}\left({ }^{\circ} \mathrm{C}\right)$ & Area II $\left({ }^{\circ} \mathrm{C}\right)$ & Area III $\left({ }^{\circ} \mathrm{C}\right)$ & Mean Value $\left({ }^{\circ} \mathrm{C}\right)$ & $\operatorname{STD}\left({ }^{\circ} \mathrm{C}\right)$ & RSD (\%) \\
\hline $1 \mathrm{~h}$ & 310.11 & 327.39 & 309.17 & 315.56 & 10.26 & 3.25 \\
\hline $2 \mathrm{~h}$ & 308.66 & 303.32 & 316.84 & 309.61 & 6.81 & 2.20 \\
\hline $3 \mathrm{~h}$ & 302.81 & 308.53 & 301.17 & 304.17 & 3.86 & 1.27 \\
\hline $4 \mathrm{~h}$ & 296.72 & 293.43 & 295.03 & 295.06 & 1.65 & 0.56 \\
\hline $5 \mathrm{~h}$ & 293.81 & 292.29 & 294.78 & 293.63 & 1.26 & 0.43 \\
\hline
\end{tabular}

TABLE 3: Combustion heat data of propellant with simple mixed nano-CuO.

\begin{tabular}{|c|c|c|c|c|c|c|}
\hline Kneading Time $(\mathrm{h})$ & Area A (J/g) & Area B (J/g) & Area $\mathrm{C}(\mathrm{J} / \mathrm{g})$ & Mean Value (J/g) & STD $(\mathrm{J} / \mathrm{g})$ & RSD (\%) \\
\hline $1 \mathrm{~h}$ & 16156 & 15741 & 15562 & 15819 & 304.6 & 1.93 \\
\hline $2 \mathrm{~h}$ & 16201 & 15839 & 15690 & 15910 & 262.8 & 1.65 \\
\hline $3 \mathrm{~h}$ & 15752 & 16216 & 16037 & 16002 & 234.0 & 1.46 \\
\hline $4 \mathrm{~h}$ & 15836 & 16202 & 16011 & 16016 & 183.1 & 1.14 \\
\hline $5 \mathrm{~h}$ & 16139 & 16331 & 15949 & 16190 & 191.2 & 1.18 \\
\hline
\end{tabular}

decomposition temperature, but also decreases the deviation of decomposition temperature.

The preparation of nano-CuO/AP composite is a predispersing method to improve the dispersity of nano-CuO in HTPB propellant. The amount of AP in the nano- $\mathrm{CuO} / \mathrm{AP}$ composite has been deducted before adding it into the propellant. Table 2 lists the decomposition temperature of $\mathrm{HTPB}$ propellant with nano-CuO/AP composite catalyst. With the similar tendency of Table 1, the mean value of decomposition temperature and RSD value in Table 2 decrease dramatically with the increase of kneading time of HTPB propellant, from $315.56^{\circ} \mathrm{C}$ to $293.63^{\circ} \mathrm{C}$ and from $3.25 \%$ to $0.43 \%$, respectively.

However, when compared with Table 1 at the same kneading time, taking 3 hours for example, all the RSD values and mean values of decomposition temperature in Table 2 are much lower. It means that the pre-dispersing method, the preparation of nano-CuO/AP composite, can effectively improve the dispersity of nano- $\mathrm{CuO}$ catalyst in HTPB propellant and decrease the decomposition temperature of HTPB propellant.

Figure 2 shows the DSC curves of AP/HTPB propellant kneaded 4 hours. Compared with the blank sample, thermal decomposition peaks of the two other samples with nano$\mathrm{CuO}$ are combined together as one peak. And the thermal decomposition temperatures are much lower than the low decomposition temperature of blank sample. With predispersing procedures, the thermal decomposition temperature of propellant with nano- $\mathrm{CuO} / \mathrm{AP}$ is $8.6^{\circ} \mathrm{C}$ lower than that of propellant with simple mixed nano- $\mathrm{CuO}$.

3.3. Combustion Heat Testing. Combustion heat data of propellant with simple mixed nano- $\mathrm{CuO}$ catalyst and with nano- $\mathrm{CuO} / \mathrm{AP}$ are contented in Tables 3 and 4, respectively. Three areas of each propellant sample have been chosen randomly to test combustion heat in $3 \mathrm{MPa} \mathrm{O}_{2}$ environment. Every combustion heat data of the three areas is a mean value of three testing data. Take the data $16,201 \mathrm{~J} / \mathrm{g}$ of area A

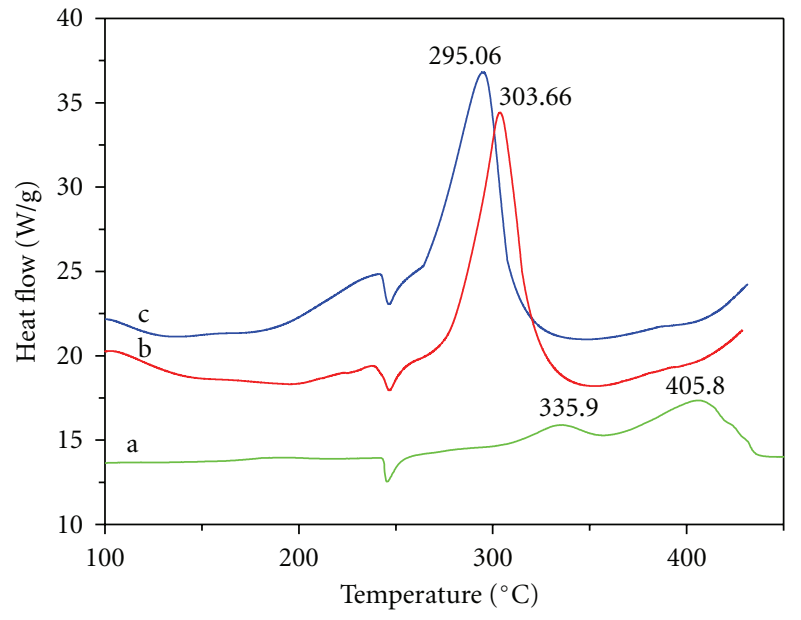

FIGURE 2: DSC curves of AP/HTPB propellant kneaded 4 hours. (a) Blank sample (b) Propellant with nano-CuO (Area 1); (c) Propellant with nano-CuO/AP (Area III).

kneading 2 hours in Table 3, for example it is the mean value of three data $15,351 \mathrm{~J} / \mathrm{g}, 16,683 \mathrm{~J} / \mathrm{g}$, and $16,569 \mathrm{~J} / \mathrm{g}$.

From the combustion data in Tables 3 and 4, as the kneading time is increasing, the RSD of combustion heat is decreasing sharply. The mean value of combustion heat in Table 3 is increased steadily with the kneading time increase. The RSD of combustion heat in Table 4 is much lower than that of in Table 3 as a whole. However, after 3 hours kneading, the mean value of combustion heat in Table 4 decreases with the kneading increase. The strange phenomenon could be speculated that the composite structure of nano- $\mathrm{CuO} / \mathrm{AP}$ in the propellant is broken gradually after $3 \mathrm{~h}$ kneading. The breaking of nano-CuO/AP leads to nano- $\mathrm{CuO}$ in the form of simple mixing in the propellant sample. Therefore, when kneading time increases to 5 hours, the combustion heat of propellant in Table 4 decreases to the value of propellant with simple mixed nano-CuO kneading 2 hours. It means that the 
TABle 4: Combustion heat data of propellant with nano-CuO/AP.

\begin{tabular}{|c|c|c|c|c|c|c|}
\hline Kneading Time (h) & Area a $(\mathrm{J} / \mathrm{g})$ & Area b $(\mathrm{J} / \mathrm{g})$ & Area c (J/g) & Mean Value $(\mathrm{J} / \mathrm{g})$ & $\operatorname{STD}(\mathrm{J} / \mathrm{g})$ & RSD (\%) \\
\hline $1 \mathrm{~h}$ & 15943 & 16230 & 15632 & 15935 & 299.2 & 1.88 \\
\hline $2 \mathrm{~h}$ & 16219 & 15788 & 16223 & 16077 & 250.2 & 1.56 \\
\hline $3 \mathrm{~h}$ & 16375 & 16259 & 16032 & 16222 & 174.5 & 1.08 \\
\hline $4 \mathrm{~h}$ & 16379 & 16003 & 16131 & 16171 & 191.2 & 1.18 \\
\hline $5 \mathrm{~h}$ & 16207 & 15722 & 15984 & 15971 & 242.8 & 1.52 \\
\hline
\end{tabular}

TABLE 5: Explosion heat of propellant with simple mixed nano-CuO.

\begin{tabular}{|c|c|c|c|c|c|c|}
\hline Kneading Time $(\mathrm{h})$ & Area $(1)(\mathrm{J} / \mathrm{g})$ & Area $(2)(\mathrm{J} / \mathrm{g})$ & Area (3) $(\mathrm{J} / \mathrm{g})$ & Mean Value (J/g) & $\operatorname{STD}(\mathrm{J} / \mathrm{g})$ & RSD (\%) \\
\hline $1 \mathrm{~h}$ & 5832 & 6089 & 6339 & 6087 & 253.5 & 4.16 \\
\hline $2 \mathrm{~h}$ & 6306 & 6402 & 6108 & 6272 & 149.9 & 2.39 \\
\hline $3 \mathrm{~h}$ & 6332 & 6517 & 6281 & 6377 & 123.9 & 1.94 \\
\hline $4 \mathrm{~h}$ & 6268 & 6049 & 6206 & 6174 & 110.9 & 1.80 \\
\hline $5 \mathrm{~h}$ & 6055 & 6121 & 6271 & 6149 & 110.6 & 1.80 \\
\hline
\end{tabular}

TABLE 6: Explosion heat of propellant with nano-CuO/AP composite.

\begin{tabular}{|c|c|c|c|c|c|c|}
\hline Kneading Time $(\mathrm{h})$ & Area (I) (J/g) & Area (II) $(\mathrm{J} / \mathrm{g})$ & Area (III) (J/g) & Mean Value $(\mathrm{J} / \mathrm{g})$ & $\operatorname{STD}(\mathrm{J} / \mathrm{g})$ & RSD (\%) \\
\hline $1 \mathrm{~h}$ & 5954 & 6336 & 6272 & 6187 & 211.8 & 3.42 \\
\hline $2 \mathrm{~h}$ & 6047 & 6371 & 6229 & 6216 & 162.4 & 2.61 \\
\hline $3 \mathrm{~h}$ & 6419 & 6491 & 6539 & 6483 & 60.4 & 0.93 \\
\hline $4 \mathrm{~h}$ & 6238 & 6281 & 6375 & 6298 & 70.0 & 1.11 \\
\hline $5 \mathrm{~h}$ & 6229 & 6245 & 6363 & 6279 & 73.2 & 1.17 \\
\hline
\end{tabular}

kneading procedure promote the reunion of nano- $\mathrm{CuO}$ after the breaking of nano- $\mathrm{CuO} / \mathrm{AP}$ composite structure.

3.4. Explosion Heat Study of Propellant. Tables 5 and 6 list the explosion heat data of propellant with simple mixed nano$\mathrm{CuO}$ catalyst and with nano- $\mathrm{CuO} / \mathrm{AP}$, respectively. With the same testing procedures of combustion heat, three areas of each propellant sample have been chosen randomly to test explosion heat in $3 \mathrm{MPa} \mathrm{N} \mathrm{N}_{2}$ environment. And each explosion heat data of the three areas is a mean value of three testing data.

In Table 5, the explosion heat of propellant with simple mixed nano- $\mathrm{CuO}$ is increased with the increase of kneading time, while the STD and RSD of explosion heat decreased. Meanwhile, the decrease ratios of STD and RSD of the explosion heat are very smooth when kneading time of propellant less than 3 hours. That is to say, after 3 hours kneading, the dispersibility of nano- $\mathrm{CuO}$ catalyst in propellant is improved to a maximum by kneading method. There is no use to improve the dispersibility of nanocatalyst by increasing kneading time for the simple mixed nano-CuO catalyst in AP/HTPB composite propellant. Other methods should be employed to improve the dispersibility of nanocatalyst in the propellant.

The tendency of the data, mean value of explosion heat, STD, and RSD, in Table 5, is very similar Table 6. The explosion heat value of these data increase with the kneading time before 3 hours, and the value decrease with the kneading time after 3 hours. The value of STD and RSD of explosion heat decreases with the kneading time less than 3 hours then increases smoothly. As the tendency of data in Table 6, one of the reasons should be the gradual breaking of the nano$\mathrm{CuO} / \mathrm{AP}$ composite particles after $3 \mathrm{~h}$ kneading, which result from the too long kneading time. The breaking changes the dispersity of nano- $\mathrm{CuO}$ in the propellant. And it provides new probabilities for reunion of nano- $\mathrm{CuO}$ catalyst particles.

However, as we can see in Table 2, there is no influence of the breaking of the nano- $\mathrm{CuO} / \mathrm{AP}$ composite particles on the thermal decomposition temperature of HTPB propellant. Far from the situation in Table 6, the decomposition temperatures of the propellants, in Table 2, are still decreasing with the increase of kneading time after 3 hours. One possible reason for this is that because the decomposition rate, or heat releasing rate, of thermal decomposition of HTPB propellant is much slower than that of combustion and explosion; the effect of the breaking of nano-CuO/AP composite on combustion and explosion is more obvious than that of thermal decomposition of HTPB propellant. Therefore, it seems that there is no or little influence on the thermal decomposition temperatures of HTPB propellants in Table 2.

Similar with the data of combustion heat testing, the explosion heat data of propellant with nano-CuO/AP composite in Table 6 is much higher than the data in Table 5 at all the kneading times. With pre-dispersing procedures, added with nano-CuO/AP composite, propellants exhibit good performance on explosion heat releasing. And the RSD values in Table 6 are less than those in Table 5. Less 
RSD value is the stand of less change, or less instability, of the explosion heat releasing of the propellant sample. It means that the propellants in Table 6 could be show higher explosion heat and more steady explosive procedures than samples in Table 5. It is only because of the predispersing procedures by adding nano- $\mathrm{CuO} / \mathrm{AP}$ composite in the propellants in Table 6 .

From the data of Table 1 to Table 6, taking kneading efficiency and heat releasing into account, the preference kneading time should be set to 3 hour for AP/HTPB composite propellant added with nano-CuO, instead of the traditional kneading time, 2 hours, for micrometer catalyst of AP/HTPB composite propellant.

\section{Conclusions}

The dispersibility of nano-CuO has been adjusted by changing the kneading time of AP/HTPB composite propellant. Nano-CuO/AP composite has been prepared, as a predispersing method of nano-CuO, to improve the dispersibility of nano- $\mathrm{CuO}$ in $\mathrm{AP}$ as well as AP/HTPB propellant. With the improvement of the dispersibility of nano-CuO, increasing kneading time or adding composite, DSC thermal decomposition temperature of AP and AP/HTPB propellant decreases markedly. However, the combustion heat and explosion heat of propellants with nano-CuO/AP, tested in $\mathrm{O}_{2}$ and $\mathrm{N}_{2}$ environment, increase then decrease on 3 hours of kneading time. This is partly because of the breaking of nano- $\mathrm{CuO} / \mathrm{AP}$ composite structure and leads to the reunion of nano- $\mathrm{CuO}$ particles.

\section{Acknowledgment}

This paper was supported by the Nature Science Foundation of China (50306008 and 50876046).

\section{References}

[1] A. A. Said and R. Al-Qasmi, "The role of copper cobaltite spinel, $\mathrm{CuxCo}_{3-x} \mathrm{O}_{4}$ during the thermal decomposition of ammonium perchlorate," Thermochimica Acta, vol. 275, no. 1, pp. 83-91, 1996.

[2] L. Liu, F. Li, L. Tan, L. Ming, and Y. Yi, "Effects of nanometer $\mathrm{Ni}, \mathrm{Cu}, \mathrm{Al}$ and $\mathrm{NiCu}$ powders on the thermal decomposition of ammonium perchlorate," Propellants, Explosives, Pyrotechnics, vol. 29, no. 1, pp. 34-38, 2004.

[3] L.-J. Chen, G.-S. Li, P. Qi, and L.-P. Li, “Thermal decomposition of ammonium perchlorate activated via addition of $\mathrm{NiO}$ nanocrystals," Journal of Thermal Analysis and Calorimetry, vol. 92, no. 3, pp. 765-769, 2008.

[4] Z. Yu, Y. Sun, W. Wei, L. Lu, and X. Wang, "Preparation of $\mathrm{NdCrO}_{3}$ nanoparticles and their catalytic activity in the thermal decomposition of ammonium perchlorate by DSC/TGMS," Journal of Thermal Analysis and Calorimetry, vol. 97, no. 3, pp. 903-909, 2009.

[5] K. Zhang, C. Rossi, G. A. Ardila Rodriguez, C. Tenailleau, and P. Alphonse, "Development of a nano- $\mathrm{AlCuO}$ based energetic material on silicon substrate," Applied Physics Letters, vol. 91, no. 11, Article ID 113117, 2007.
[6] K. Zhong, P. Jin, and Q. Chen, "Ni hollow nanospheres: preparation and catalytic activity," Journal of Nanomaterials, vol. 2006, Article ID 37375, 7 pages, 2006.

[7] Y.-H. Hu, J.-P. Liu, J. Xu, and D.-Z. Wang, "Dispersion mechanism of nano-magnetite coated with oleate in aqueous carrier," Journal of Central South University of Technology, vol. 15, no. 5, pp. 663-668, 2008.

[8] M. Kawaraya, "Dispersibility of nano- $\mathrm{TiO}_{2}$ paste with fine ceramic beads and morphology of the mesoporous film," Journal of Chemical Engineering of Japan, vol. 40, no. 3, pp. 255-258, 2007.

[9] J. K. Kim, D. Z. Wo, L. M. Zhou, H. T. Huang, K. T. Lau, and M. Wang, "Dispersibility and degradation properties characterization of nano titanium dioxide photocatalysis material," Key Engineering Materials, vol. 334-335, pp. 565568, 2007.

[10] G. Duan, J. Zhu, C. Kan, X. Yang, L. Lu, and X. Wang, "Preparation of novel structural nanosized $\mathrm{Y}_{2} \mathrm{O}_{3}$ powders and their catalytic activity on the decomposition of $\mathrm{NH}_{4} \mathrm{ClO}_{4}$," Reaction Kinetics and Catalysis Letters, vol. 92, no. 2, pp. 247256, 2007.

[11] V. F. Komarov, "Catalysis and inhibition of the combustion of ammonium perchlorate based solid propellants," Combustion, Explosion and Shock Waves, vol. 35, no. 6, pp. 670-683, 1999. 

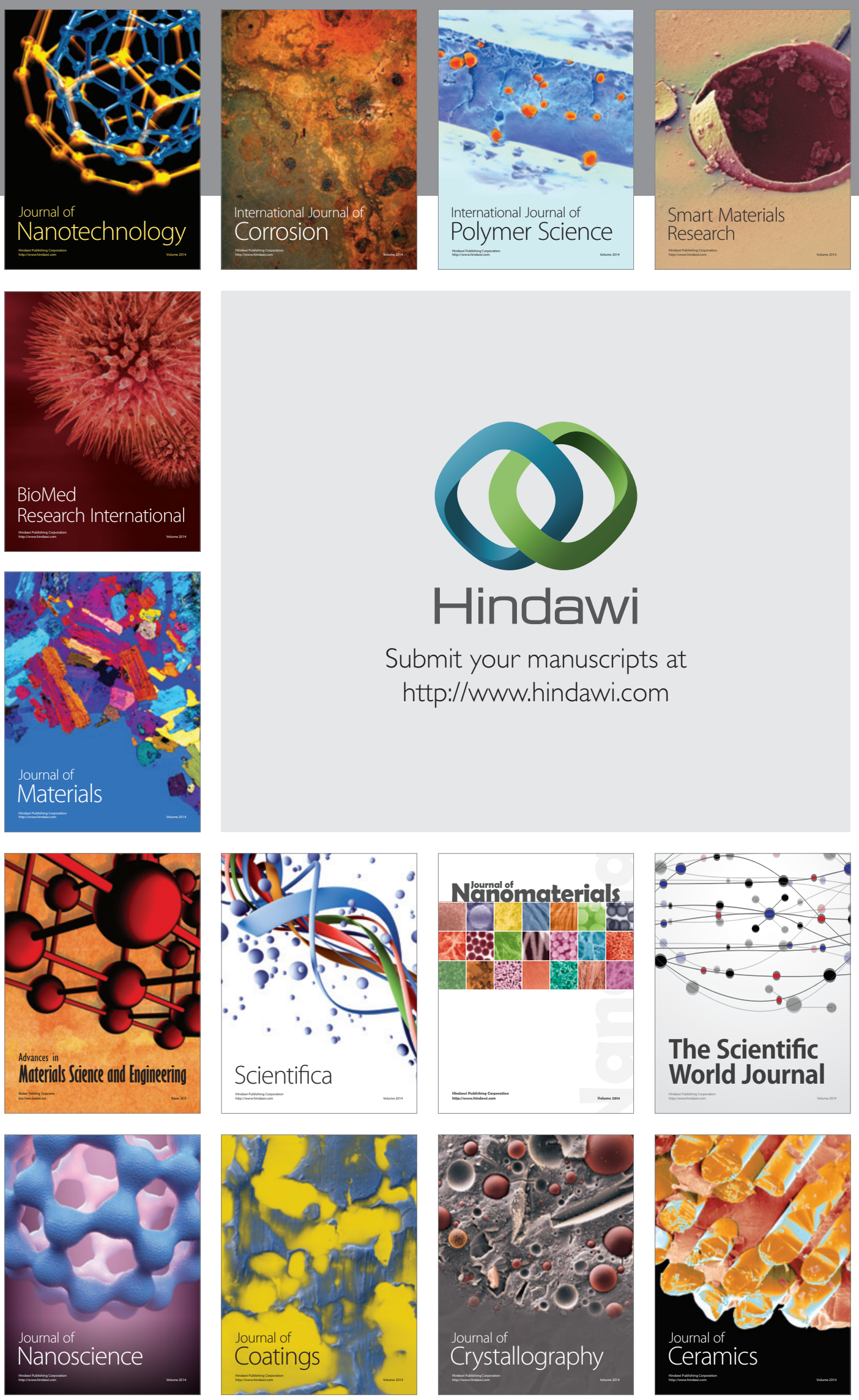

The Scientific World Journal

Submit your manuscripts at

http://www.hindawi.com

\section{World Journal}

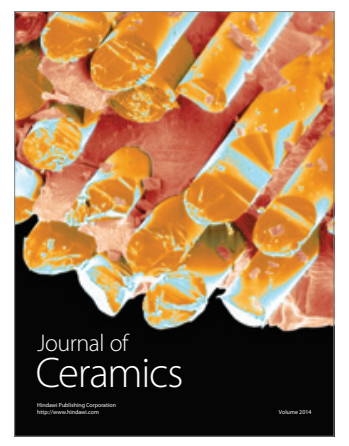

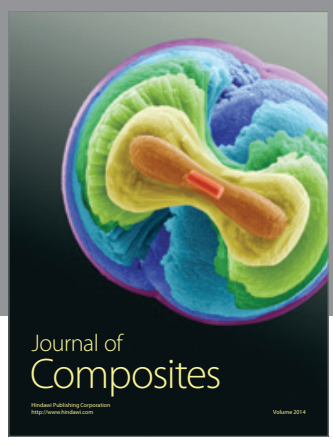
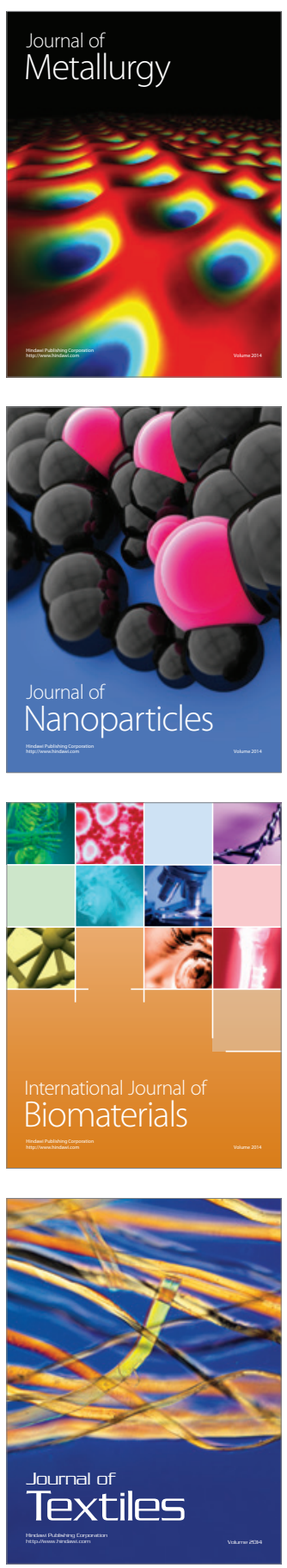